\title{
Correction to: Methodology for Detecting Cyber Intrusions in e-Learning Systems during COVID-19 Pandemic
}

\author{
Ivan Cvitić ${ }^{1}$ (D) - Dragan Peraković ${ }^{1}$ (D) Marko Periša ${ }^{1}$ (D) A Anca D. Jurcut ${ }^{2}$ (D)
}

Accepted: 2 December 2021

○) Springer Science+Business Media, LLC, part of Springer Nature 2021

\section{Correction to: Mobile Networks and Applications (2021)} https://doi.org/10.1007/s11036-021-01789-3

The original version of this article, published on 6 June 2021, the authors have found an error in the published verOriginal article has been corrected. sion of the paper. Figure 6 is duplicated and the same image is captured as figure 5 . Correct figure 5 is shown below.

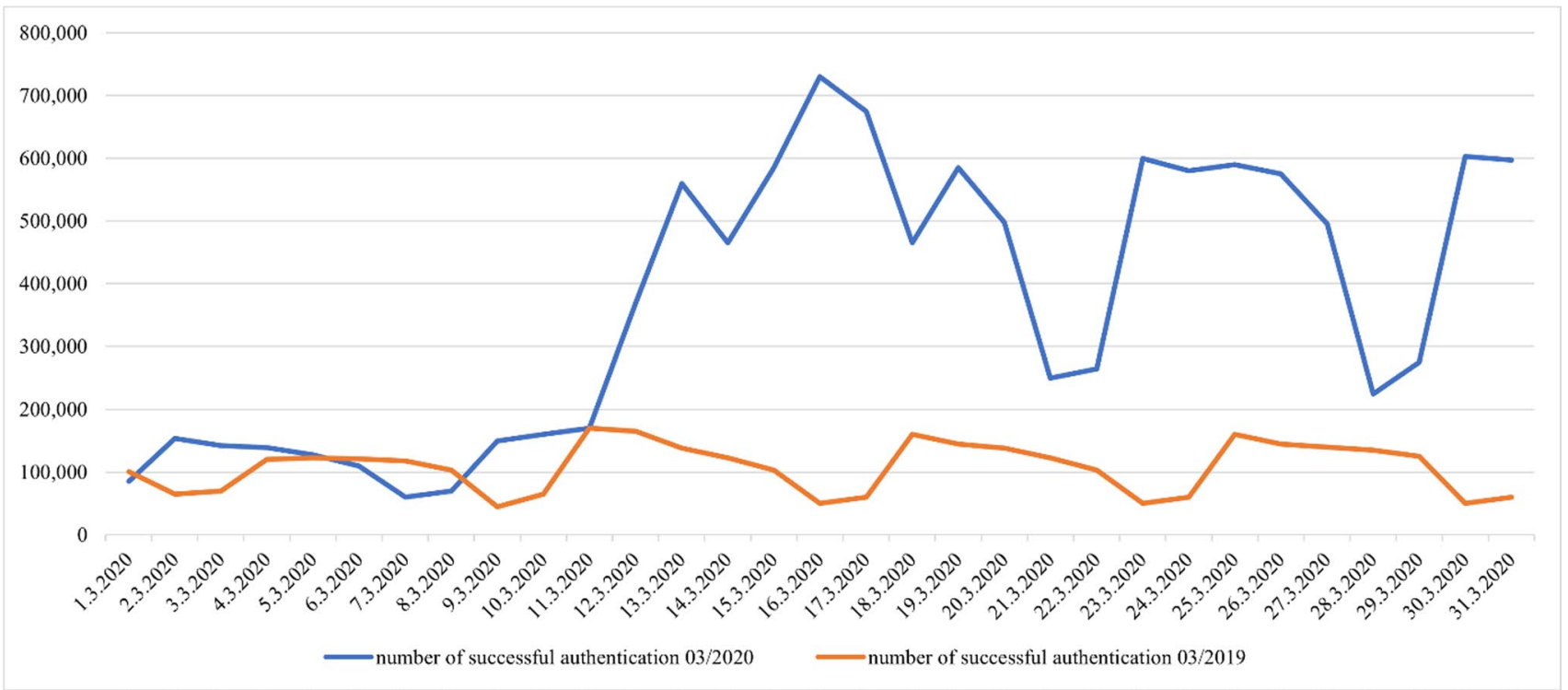

Fig 5 Number of successful authentications of March 2019 and 2020 comparison

The original article can be found online at https://doi.org/10.1007/

Publisher's Note Springer Nature remains neutral with regard to s11036-021-01789-3.

\section{Ivan Cvitić}

ivan.cvitic@fpz.unizg.hr

1 Faculty of Transport and Traffic Sciences, University of Zagreb, Vukelićeva 4, 10000 Zagreb, Croatia

2 School of Computer Science and Informatics Belfield, University College Dublin, Dublin 4, Ireland 